\title{
TUBERCULOSIS CONTROL PROGRAMME IN NEPAL (PART 2) CONCRETE STRATEGY
}

\author{
YOSHIO HIROTA ${ }^{1)}$, J. N. GIRI ${ }^{2)}$, N.L. MASKAY ${ }^{3)}$, B. R. BAIDYA ${ }^{4}$, \\ G. M. BAJRACHARYA ${ }^{5)}$, HIDEO NAKANO ${ }^{6)}$ AND \\ YASUAKI NISHIJIMA ${ }^{7)}$
}

(Received for publication March 4, 1977)

A concrete strategy for Tuberculosis control programme on the total population of 280,000 in Syanja District of Gandaki Zone, Nepal, was discussed.

The programme, manned by 25 members, started October 17, 1976, will be enforced on the following items until April 12, 1977. tion).

1. BCG vaccination of children under 15 years of age (Direct Vaccina-

2. Case finding by direct smear examination of sputum and the medical treatment of patient found.

The levels of prevention of Tuberculosis in developing countries, like Nepal, are of course not necessary to be relied on the sophisticated latest medical technology. Smear test of sputum for example will be done before chest X-ray examination can be carried out.

In a country where the budgetary allowances can not allocate periodical chest X-ray examination, the mass vaccination of BCG to the young population and case finding survey followed by sputum examination will be most suitable and pertinent levels of application in preventing Tuberculosis infection.

\section{INTRODUCTION}

(See Figs. 1 and 2)

The census in 1971 showed that out of $11,560,000$ of a total population in Nepal, 2,800,000 live in the Eastern
Region, 3,870,000 live in the Central Region, 2,470,000 live in the Western Region where the Japanese Government received the request for the medical collaboration aid, and 2,430,000 live in the Far Western Region.

1) Department of Public Health, Kurume University School of Medicine, Kurume, 830, Japan

2) Chief, National Tuberculosis Control Project, Kathmandu, Nepal

3) Chief, Central Chest Clinic, Kathmandu, Nepal

4) Civil Surgeon, Gandaki Zonal Hospital, Pokhara, Nepal

5) Chief, Western Regional Health Laboratory, Pokhara, Nepal

6) Central Radiological Section, Kurume University Hospital

7) Central Laboratory Section, Kurume University Hospital

1), 6) \& 7): Members of Japanese Medical Cooperation Team (JMCT) Based on the Colombo Plan. 

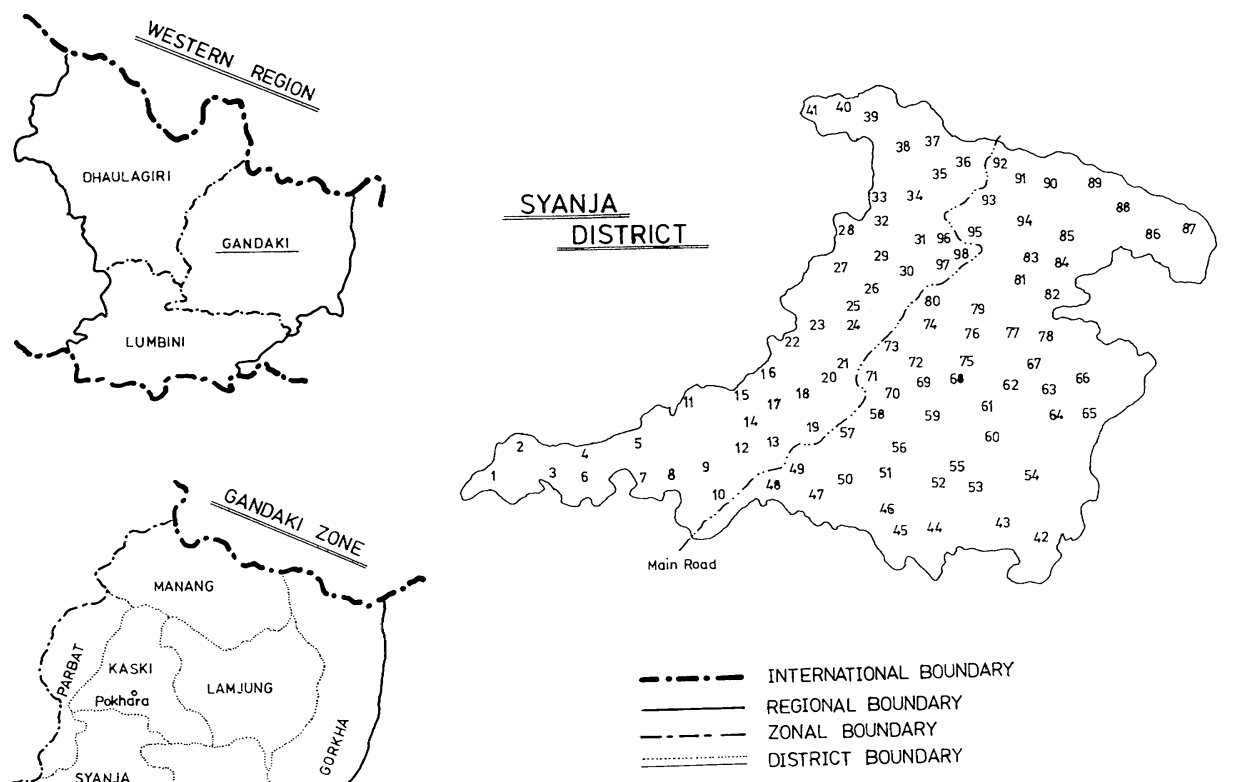

Fig. 1

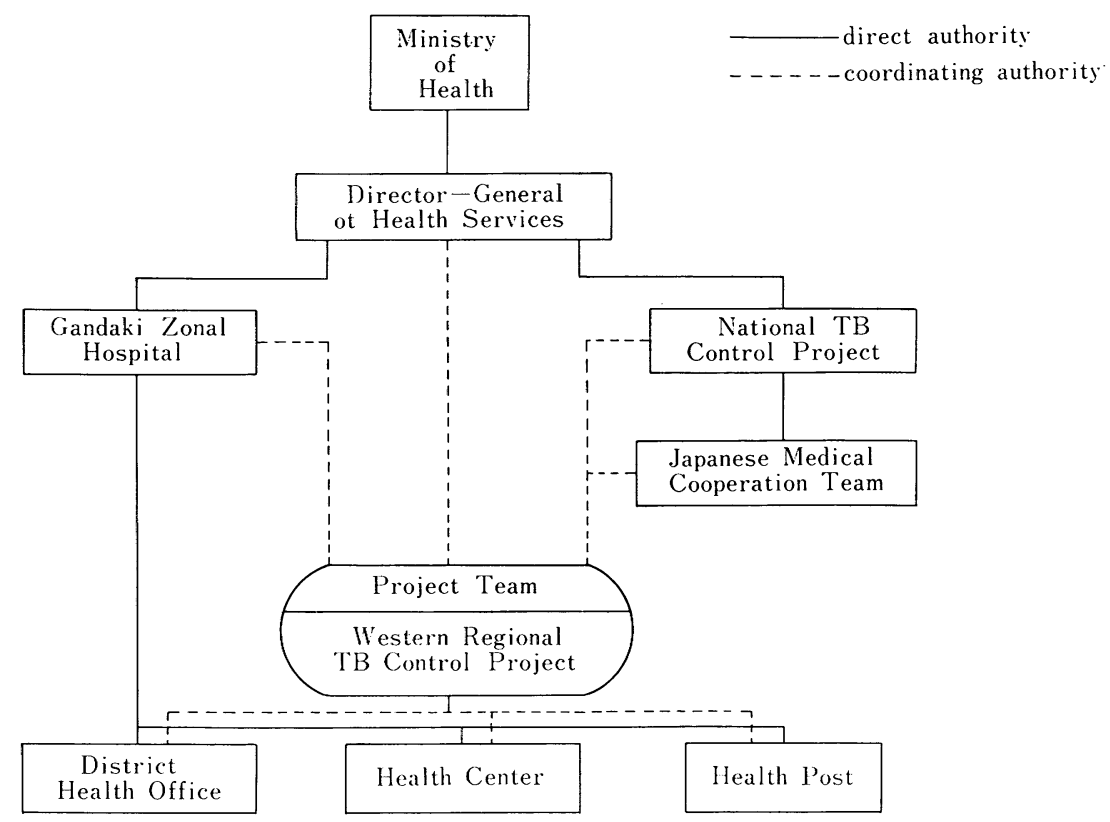

(referred to WHO: Health project management, 1974. Page 175)

Fig. 2 The project organization concept. 
The discussions with the Ministry of Health, the National Tuberculosis Control Project and other authorities concerned with His Majesty's Government of Nepal defined that the Japanese Medical Cooperation Team would establish the Western Regional Tuberculosis Control Project at Pokhara and carry out the tuberculosis control programme in Syanja District keeping the manpower provided by the National Tuberculosis Control Project.

Syanja District, with a total population of 280,000 , is about 30 miles distant south-westward from Pokhara, which is situated at the center of the Western Region, and none has started work on tuberculosis control in this area because this district has the biggest population in the Western Region and is located in a remote and secluded place in the mountains.

Syanja District consists of 98 "Panchayat"s (the village unit administered by a committee of 5 members), and it is presumed that the number of children under 15 years of age eligible to be innoculated with BCG is about 112,000 , and suspected case are about $2,800,1 \%$ of Syanja's total population.

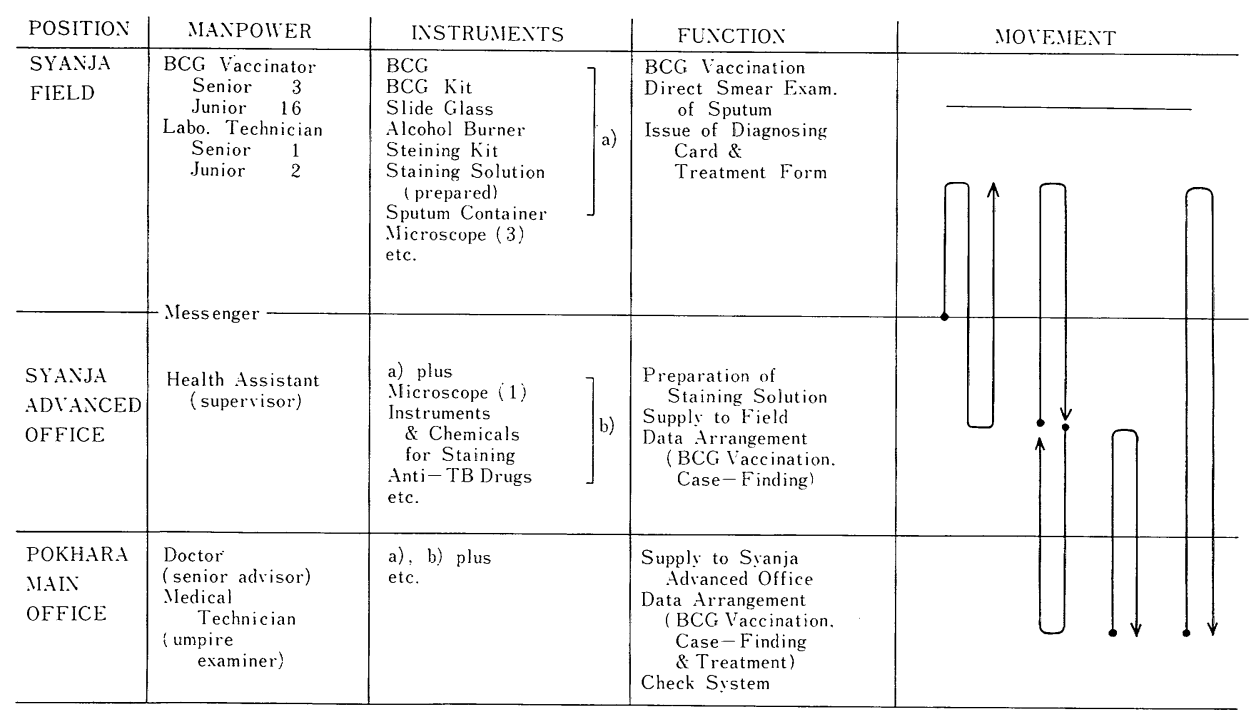

Fig. 3 Design of project.

\section{CONCRETE STRATEGY}

(See Figs. 1 and 3, Table 1)

\section{a) Period}

October 17, 1976 to April 12, 1977.

\section{b) Subject}

Total population of 280,000 settled in Syanja District.

\section{c) Enforcement items}

BCG vaccination of children under 15 years of age (Direct Vaccination), case-finding by direct smear examination of sputum and treatment.

\section{d) Manpower}

25 members consisting of one Doctor (as a senior adviser) and one Medical 
Technician (as an umpire examiner) from JMCT, and one Health Assistant (as a supervisor in the field), one Senior Laboratory Technician, two Junior Laboratory Technicians, three Senior BCG Vaccinators and sixteen Junior BCG Vaccinators.

The total number of Laboratory Technicians and BCG Vaccinators will be doubled from March 14, 1977.

\section{e) Distribution of manpower}

The Senior Adviser and Umpire Examiner stay at the Pokhara Main Ofíice and the Supervisor at the Syanja Advanced Office. The BCG Vaccinators are divided into 4 or 5 teams and visit houses all over the Syanja District. The Laboratory Technicians move from one panchayat to another panchayat while working at the centre of each group of BCG Vaccinators.

\section{f) Activity}

In the order demonstrated in Fig. 1 and Table 1, one temporary base is set up in each of three panchayats and each Laboratory Technician sets up the instruments there. BCG Vaccinators visit all the houses of neighbouring panchayats from the bases to give BCGs and collect sputum specimens from symptomatic cases. Collected sputum specimens are fixed at the spot and brought back to the bases by BCG Vaccinators, and Laboratory Technicians examine them at the base.

As soon as a case who has a positive sputum smear is found, a diagnosing card and treatment form the Central Chest Clinic, which is one of the most authoritative special hospitals in the field of chest diseases in Kathmandu, are issued to that case.

Patients visit the nearest health posts or other health institutions, where standard anti-TB drugs mentioned in the former report (1977) have been distributed in advance, arming themselves with these cards and forms. The staff members of the health institutions discuss with the patient and select the most appropriate prescription out of three kinds of regimens for that patient.

\section{g) Logistical system}

The necessary instruments and chemicals for the BCG innoculation and direct smear examination, BCG, slide glass, staining chemicals, etc., are stored at the Pokhara Main Office and supplied to the Syanja Advanced Office as occasion demand. The Advanced Office has uncomplicated laboratory equipment which renders it possible to do a direct smear examination and staining solution preparation, and supplies the instruments and prepared chemicals to the Syanja Field.

One messenger which doubles as a porter walks around with the Laboratory Technicians and BCG Vaccinators in the Syanja Field and is charged with the supplying of necessary instruments between the Field and the Advanced Office once a week.

\section{h) Checking system}

Accuracy of case-finding : All of the smear slides which have been prepared and examined in the field are transported to the Advanced Office by the messenger once a week and reexamined by the Umpire Examiner. The Umpire Examiner goes into the field for a short time periodically and tests the whole process of sputum collection, smear slide preparation and microscopic examination with Laboratory Technicians and BCG Vaccinators.

Accuracy with which the detected 
TABLE 1

Mass BCG and case-finding advance programme

\begin{tabular}{|c|c|c|c|}
\hline Panchayat & Jo. of house & Panchayat & No. of house \\
\hline 1. Kaikot & 606 & 53. Kyacmi & 970 \\
\hline 2. Kotakot & 236 & 54. Jagat Bhanjang & 598 \\
\hline 3. Alam Devi. & 376 & 55. Baling & 899 \\
\hline 4. Bikgha Chale & 369 & 56. Armati Dhanubans & 449 \\
\hline 5. Miramid Hau & 370 & 57. Alam Devi & 376 \\
\hline 6. Beagha Bhanjang & 406 & 58. Chinne Bas & 822 \\
\hline 7. Krishna Gandaki & 854 & 59. Tarli Bhanjang & 374 \\
\hline (17th Oct. to 5th Nov., 1976) & & 60. Kich Nash & 381 \\
\hline 8. Balam Jagata Devi & 542 & 61. Pyar sing & 377 \\
\hline 9. Bam Bhanjang & 639 & 62. Dunjhya Thanti & 521 \\
\hline 10. Maling & 899 & 63. Chibe Bhanjang & 253 \\
\hline 11. Pidikhala & 606 & 64. Chisopani & unknown \\
\hline 12. Pilakot & 496 & 65. Kich Nasdevisthan & 389 \\
\hline (16th Nov. to 14th Dec., 1976 & & 66. Metha Bhurung & 625 \\
\hline 13. Chok Thana & 369 & 67. Mejha Kot & 379 \\
\hline 14. Ghurukha Danda Khark & 346 & 68. Damung Khanti & 449 \\
\hline 15. Sikskot Deurali & 466 & 69. Bani Thok & 604 \\
\hline 16. Kolthok Thumka & 469 & 70. Dahathum & 710 \\
\hline 17. Thum Pokhare & 498 & 71. Pyeleka Chaur & 511 \\
\hline 18. Bahakot & 398 & 72. MalBhul & 317 \\
\hline 19. Bhurem Bot & 444 & 73. Archale Bhanjang & 359 \\
\hline (15th Dec., 1976 to 13th Jan., & , 1977) & 74. Orent & unknown \\
\hline 20. Sorek Mahapor & 480 & 75. Sal Danda Hatiya & 439 \\
\hline 21. Gadera & 533 & 76. Rang Bhang & 276 \\
\hline 22. Dhapuk Samal Banjang & 481 & 77. Karen Danda & 574 \\
\hline 23. Khai Deurali & 573 & 78. Baha Kot & 308 \\
\hline 24. Khatesetal Chaupati & 431 & 79. Dhuladi & 432 \\
\hline $\begin{array}{l}\text { 25. Myal Tari } \\
\text { (14th Jan. to 11th Feb., 1977) }\end{array}$ & 602 & $\begin{array}{l}\text { 80. Lume Chapkhor Danda } \\
\text { 81. Takshar }\end{array}$ & $\begin{array}{l}225 \\
\text { unknown }\end{array}$ \\
\hline 26. Rapa Kot & 826 & 82. Bharat Pokhari & 494 \\
\hline 27. Sirubari & 643 & 83. Bhote Pokhari & 534 \\
\hline 28. Satu Rang Bhanjang & 642 & 84. Sani Nirmal & 501 \\
\hline 29. Satu Pashal & 541 & 85. Phom Shin & 316 \\
\hline 30. Satau Darau & 490 & 86. Kisti Nachane Chour & 507 \\
\hline (12th Feb. to 13th Mar., 1977 & & 87. Bhatti Khan & 431 \\
\hline 31. Majhajri & 266 & 88. Dan Goth & 412 \\
\hline 32. Chailaunebas & 343 & 89. N. Deurali & 472 \\
\hline 33. Range Thanti & 529 & 90. Pouwa Gouda & 426 \\
\hline 34. Bhatkhola & 347 & 91. Ganesha Pur & 464 \\
\hline 35. Arukharka & 349 & 92. Seti Dowan & 474 \\
\hline 36. Rapa Kot & 826 & 93. Lamange & 317 \\
\hline 37. Bagsing Deurali & 453 & 94. Putalikhet Syanja & 462 \\
\hline 38. Khalte Sitalch & 431 & $95 . \quad 11$ & unknown \\
\hline 39. Rani Chaur Dadakhark & 204 & 96. & unknown \\
\hline 40. Silmi Rani Swara & 196 & 97. & unknown \\
\hline 41. Sakar Mohame & 399 & $98 . \quad 11$ & unknown \\
\hline 42. Sakar Pathsar & 440 & \multicolumn{2}{|c|}{ (14th Mar. to 12th Apr., 1977) } \\
\hline 43. Chapa Kot & 457 & & \\
\hline 44. Chapa Kot Ratnapur & unknown & \multicolumn{2}{|l|}{ Total No. of Panchayats: 98} \\
\hline 45. Kuwa Kot & 706 & \multicolumn{2}{|c|}{ Total No. of Populations: 280,064} \\
\hline 46. Geja Maumukhe & $\begin{array}{l}390 \\
538\end{array}$ & \multirow{2}{*}{\multicolumn{2}{|c|}{ Working Days: 25 Days per Month }} \\
\hline $\begin{array}{l}\text { 47. Tulsi Bhanjang } \\
\text { 48. Nindo Bato }\end{array}$ & $\begin{array}{l}538 \\
\text { unknown }\end{array}$ & & \\
\hline 49. Pek Bali & 592 & & \\
\hline 50. Kewor Bhanjang & 548 & & \\
\hline 51. Desing Kot & 438 & & \\
\hline 52. Sikham & 685 & & \\
\hline
\end{tabular}


patients contact to the health institutions and complete the treatment: Each health institution reports the number of patients who have come with the diagnosing card and treatment form from the Central Chest Clinic, and their states of treatment, to the Syanja Advanced Office or the Pokhara Main Office.

\section{i) Others}

All datum gained in the field, the number of BCGs given, the number of sputum smear examinations done, the number of sputum smear positive cases, etc., are reported to the Syanja Advanced Office through the messenger and to the Pokhara Main Office through the Advanced Office.

\section{DISCUSSION}

It seems that not a few health projects, without reference to their variety in size, are haunted with failure. Although it goes without saying that "Pilot Project", which is the project for the following progressive countermeasures, has taken it for granted that it cannot estimate how it has contributed to solving the health problem, it does appear that there were also some other health projects which did not estimate whether they had improved health, made health services or achieved their goals.

It is said that in many cases, the failures can be traced to one or more shortcomings in management such as :

- inadequate provision for implementing plans

- incorrect selection of programme strategies and methods

- inattention to political and organizational limitations on change

- failure to link objectives with specific deadlines
- inability to get collaborative work accomplished by a number of established organizational units

- dispersion of resources and targets so widely that little impact is made on problems

- overoptimism about the capacity of the infrastructure to carry out the plans

- overreliance on intuition in defining and analysing problems and possible solutions

- failure to monitor progress and identify problems in carrying out plans, and to prevent shortfalls or make them up promptly

- failure to develop manpower and other resources adequately

- failure to match programme techniques with consumer needs and characteristics, resulting in a lack of acceptance

- failure to involve early all who should contribute to planning

- inattention to budgetary cycles and processes as they affect planning and implementation (1975).

To avert the failure attributed to the factors mentioned above, planning and implementation should be cautiously conducted on the basis of the public health diagnostics.

As demonstrated in Fig. 4, this strategy was planned with reference to Nepal's own vital statistcs (1974), the investigation into the actual conditions of tuberculosis and its control (1976), the former example of large-scale tuberculosis control (1974) and the ninth report of the WHO Expert Committee on Tuberculosis (1974) (Evaluations or Studies, or, Country Health Programme), logistical system and checking system grounded upon the geographical condition of Syanja District and its geographical relationship to Pokhara (Random Idea), and the resources donated by the Japanese Government and 


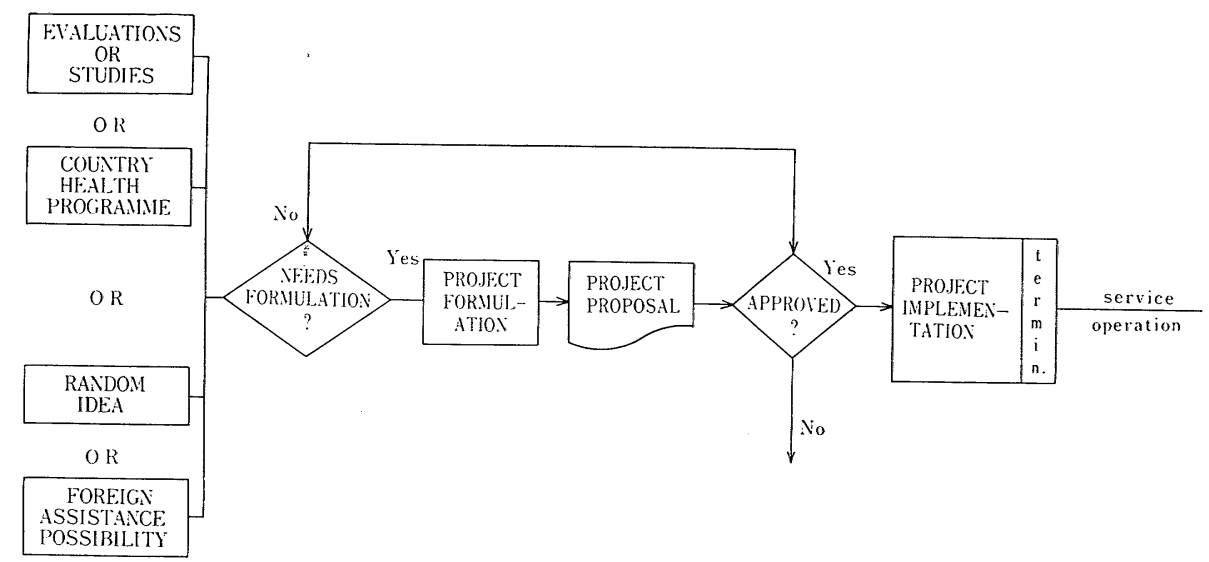

(WHO : Health project management, 1974. Page 2)

Fig. 4 Project management.

the future donation (Foreign Assistance Possibility).

Planning the health project, it is necessary that the natural history of the target disease should be understood, and for early detection and early treatment, it is also necessary that the behavioral sciences on the human side in the period of onset, diagnosis, treatment and recovery should be understood (See Fig. 5). For what with the risk that the tuberculosis patients who remain to be diagnosed are really an infectious focus in themselves, and what with the case-finding difficulties against the "Rapid Cases" (1972), the behavioral sciences on tuberculosis patients in this period become all the more important.

D. Banerji et al. (1963) assumed that there are various levels of consciousness or awareness of symptoms, and divided them into three categories:

a) mere consciousness of the presence of one or more isymptoms, hereafter called "consciousness" ;

b) awareness of one or more symptoms as a source of worry, hereafter called "worry awareness";

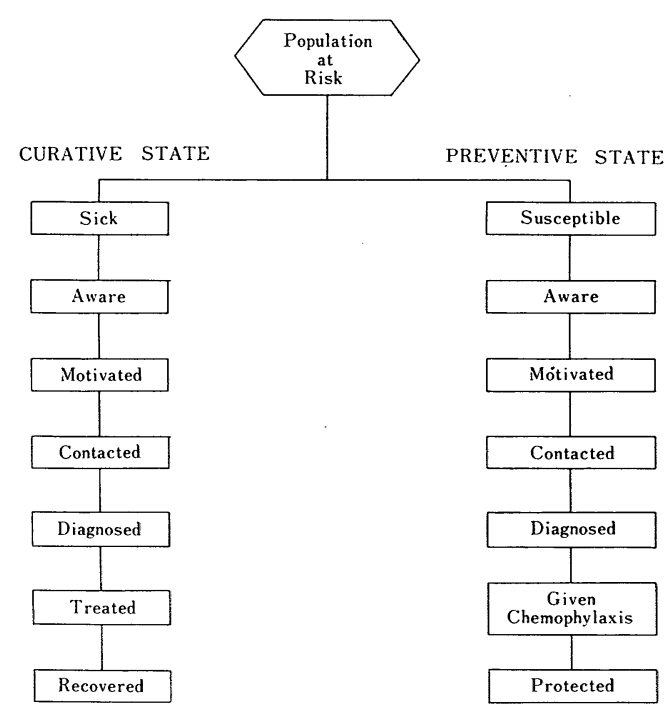

(WHO: Health project management, 1974. Page 107)

Fig. 5 Health problem model.

c) awareness of symptoms which leads to action, hereafter called "action".

House visitation and interviews to collect sputum specimens from sympto- 
matic cases will render it possible to detect tuberculosis cases conforming to categories a) and b), whom health institutions cannot detect, and also be the effectual method for "Rapid Cases".

In the present project, the "Door to Door" method for case-finding has been adopted owing to much cooperation of authorities with Nepal. While on this project, throughgoing surveillance should be carried out and the ideal model of tuberculosis control should be sought.

\section{REFERENCES}

BAinbridge, J. and SAPIRIE, S. (1974). Health project management. A manual of procedures for formulating and implementing health projects. Wld. Hlth. Org. Geneva.

BAner Ji, D. and Andersen, S. (1963). A sociological study of awareness of symptoms among persons with pulmonary tuberculosis. Bull. Wld. Hlth. Org., 29, 665-683.
Hirota, Y., Giri, J.N., Maskay, N.L., Baidya, B.R., Bajracharya, G.M, Nakano, H. and Nishijima, Y. (1977). Tuberculosis control programme in Nepal (Part 1). contributed to Kurume Med. J.

His Majesty's Government of Nepal (1976). The formula of tuberculosis control project. National Planning Commission Secretariat (1974). Central bureau of statistics, Kathmandu, Nepal: STATISTICAL POCKET BOOK.

Schaefer, M. (1975). A management method for planning and implementing health projects. WHO Chronicle, 29, 18-23.

Toman, K. (1972). Case finding of tuberculosis. Adv. Tuberc. Res., 18, 103-147.

WaAler, H.T., Gothi, G.D., Baily, G. V.J. and NAIR,S S. (1974). Tuberculosis in rural South India. A study of possible trends and the potential impact of antituberculosis programmes. Bull. Wld. Hlth. Org., 51, 263-271.

WHO Expert Committee on Tuberculosis (1974). Ninth Report: World Health Organization Technical Report Series No. 552, WHO, Geneva. 